\title{
SETENTA Y CINCO AÑOS DEL CENTRO UNIVERSITARIO
}

\author{
Almagro García, Antonio
}

Celebramos a lo largo de 2019 el septuagésimo quinto aniversario de la creación en 1944 del hoy Centro Universitario "Sagrada Familia», en sus orígenes Seminario de Maestros; celebración más que justificable y necesaria por dos razones: la primera, para agradecer y alegrarse por la existencia de una institución cuyo objetivo esencial es y ha sido desde el mismo momento de su fundación ofrecer educadores para y a la sociedad; y, la segunda, para honrar y distinguir a los cientos de maestros y maestras salidos de sus aulas. Un alumno de la primera promoción (don Antonio Domínguez) así nos lo cuenta:

Corría el mes de noviembre de 1944 cuando nos reunieron a veinticuatro niños. Todos ellos de familias que no podían soñar con darles a sus hijos nada más que estudios primarios. Estos alumnos provenían de Alcalá, Baena, Úbeda, Granada, Villacarrillo... Rostros asustados y sollozos por la noche mientras dormíamos en aquel pabellón habilitado al efecto. Formábamos un grupo de niños tristes que pronto cambiaríamos la pena por la alegría.

Los catorce de más edad pasamos a $1^{\circ}$ de Magisterio y los diez restantes al curso preparatorio.

Sabréis que los años 44, 45 y siguientes fueron dificilísimos para España. La gente moría de hambre. Nosotros también la padecimos, pero dentro de lo que cabe fuimos privilegiados. Hacíamos las comidas reglamentarias y a algunos "debiluchos» les daban una taza de caldo durante los recreos para que resistiesen hasta el mediodía.

Eran tiempos de enorme escasez, carecíamos de lo imprescindible. El profesor de literatura pedía libros a señores particulares para que pudiésemos leer, comentar y resumir obras literarias.

Recuerdo la seriedad de los exámenes trimestrales y finales. Unos eran escritos y otros orales. En éstos se nos exigía presentarnos ante el tribunal con corbata. Dos corbatas eran suficientes para todos. Cuando un alumno terminaba su examen, la dejaba en el picaporte del aula, donde la recogía el que esperaba turno.

¿Cómo no recordar a $D^{a}$ Anita y $D^{a}$ Catalina?, que además de haber donado el chalé de Villanueva y otras propiedades, nos hacían la comida, nos la servían $y$, ayudadas por la sin par Fuensanta, nos enjabonaban de pies a cabeza, ya que no teníamos duchas. 


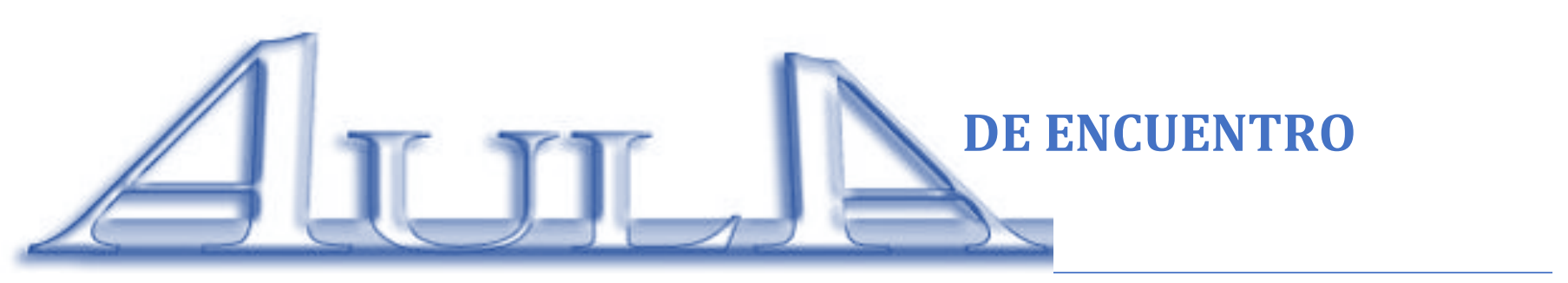

Almagro García, A. (2019). Setenta y cinco años del Centro Universitario. Aula de Encuentro, no 21, volumen 1, pp. 1-4.

DOI:

A pesar de todo, la Escuela de Magisterio, llamada Seminario de Maestros, fue aumentando su alumnado y tuvo que trasladarse a Úbeda'.

Estuvo el Seminario en Villanueva hasta el curso 1947-1948, y a comienzos del curso 1948-1949 se trasladó a Úbeda, no sin problemas ni dificultades, alegándose como razón última del cambio la imposibilidad de albergar en Villanueva al creciente número de alumnos $\mathrm{y}$, también, los medios que ofrecían las nuevas instalaciones de Úbeda, sede oficial de la Fundación SAFA, que se construían con más amplitud y ambición.

Villoslada:

En el año 2019, pues, cumplimos los primeros 75 años del sueño del padre

Las Escuelas Profesionales de la "Sagrada Familia» vienen desarrollando una labor creciente de formación desde su fundación en 1940. Pero para el sostenimiento y mayor extensión de estas Escuelas, se necesitan Maestros perfectamente preparados, que tomen su función docente con verdadero interés vocacional y apostólico. Maestros además que posean a fondo los recursos de la moderna Pedagogía y conozcan no sólo las asignaturas que han de enseñar [...] sino todos aquellos conocimientos que merecen a un hombre el respeto y las atenciones de persona culta.

Pretendemos que nuestros maestros eleven el nivel medio de las Escuelas por ellos regentadas y para esto es indispensable que su nivel personal en vida espiritual, en educación, en conocimientos científicos e históricos, en la formación de su temperamento artístico sea también elevado.

Más todavía. Aun el Maestro rural debe tener una cultura muy por encima del medio en que vive para poder influir eficazmente en el mismo. La misma naturaleza de las cosas exige que el Sacerdote y el Maestro sean los educadores de los demás hombres, y por lo tanto que de ellos resulte a la larga el levantamiento espiritual y moral o la decadencia de los pueblos ${ }^{2}$.

Son estas palabras, sin fecha conocida aunque cercana a la de la fundación de SAFA, las que marcan la idea fundacional del hoy Centro Universitario. En realidad, dicho con otras palabras, creación de un centro propio de formación de maestros con intensa y profunda preparación en vida espiritual, en educación, en conocimientos científicos e históricos y en formación artística, con una marcada vocación educativa y apostólica y con conocimiento de la moderna Pedagogía: y la concepción del maestro como instrumento necesario para el cambio social por ser educador de los demás hombres y mujeres a través de su levantamiento espiritual y moral. O lo que es lo mismo, según el paradigma educativo ignaciano, educar a personas Conscientes de si mismas y del mundo en que viven, Competentes para afrontar los problemas técnicos, sociales y humanos a los que se enfrenta todo profesional, Comprometidas con la construcción de un mundo mas justo y Compasivas y abiertas al sentido de la existencia y a la cuestión de Dios. O dicho de otro modo, según el paradigma Ledesma-

1. Taboada Velasco, R. (2004). La SAFA de Villanueva del Arzobispo en el sesenta aniversario de su fundación. Aula de Encuentro, n 8 , pp. 181-182.

2. Archivo SAFA Escuela Universitaria Profesorado (SASEUP) 1, Planes de estudio SAFA: Reglamento General y Plan de Estudios de la Escuela de Magisterio de la «Sagrada Familia», pp. 1 y 2. 


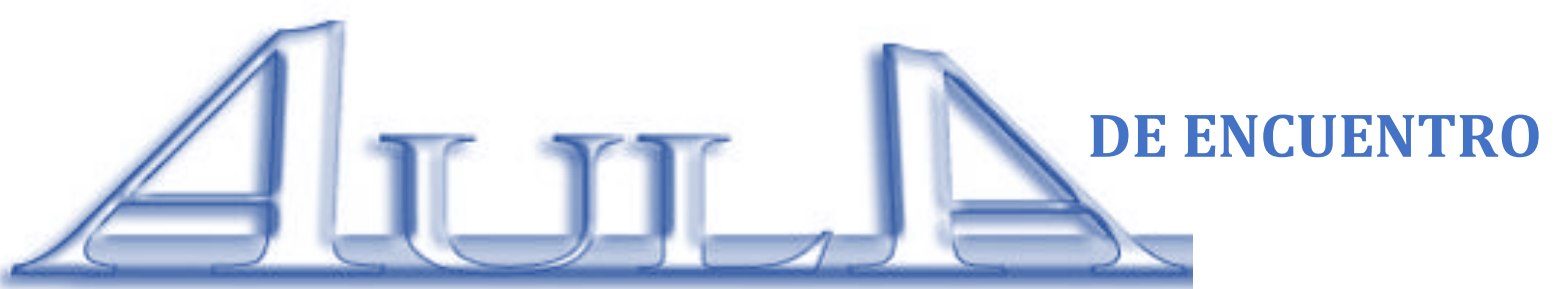

Almagro García, A. (2019). Setenta y cinco años del Centro Universitario. Aula de Encuentro, n 21, volumen 1, pp. 1-4.

DOI:

Kolvenbach, una educación que incida en las cuatro finalidades últimas de la educación de los jesuitas: utilitas, iustitia, humanitas y fides, traducidas en:

- Una educación útil, que proporcione a los estudiantes los instrumentos necesarios para ser personas de valía en el terreno profesional.

- Una educación humanista, que proporcione a los estudiantes una formación integral en valores humanos, que cultive su ser personal.

- Una educación para la justicia, que cuide la sensibilidad para percibir y pensar críticamente, para obrar en conciencia, para juzgar y actuar a favor de los derechos de las personas.

- Una educación creyente que cultiva la dimensión transcendente de la persona, que proporcione información y experiencias para que el estudiante pueda asumir razonablemente la fe, respetando la libertad religiosa.

Con un numero cercano a los 200 profesores a lo largo de su historia y con algo más de 7.000 alumnos formados en sus aulas que, no sólo han fomentado y desarrollado una importante labor trabajando en los distintos centros SAFA y en otros muchos de Andalucía y de España, sino también y, por múltiples razones, "colonizando» espacios, ambientes, trabajos y actividades, no necesariamente educativos.

Hasta siete planes de estudio se han implantado en su historia: el inicial, y los de los años 1950, 1967, 1973, 1995 y 2000, para llegar al hoy en vigor Plan Bolonia. Desde 1973 se constituye como centro universitario (la primera presencia de la Universidad en Úbeda), adscrito a Granada y, posteriormente, a Jaén. A lo largo de su historia se ha denominado Seminario de Maestros (1944-1945), Escuela de Magisterio de la Iglesia «Sagrada Familia» (1949-1973), Escuela Universitaria del Profesorado de EGB (1973-2000), Escuela Universitaria de Magisterio (2000-2010) y, actualmente, Centro Universitario «Sagrada Familia».

Pero todo esto no dejan de ser datos estadísticos. Lo realmente importante han sido y son las constantes siempre presentes en su IR HACIENDO CAMINO, en su forma de ser, de estar y de actuar; a saber:

- La permanente presencia de la idea fundacional como continuo existencial, con la sostenida tutela de los principios de la Fundación SAFA y de la Compañía de Jesús.

- El firme deseo de renovación (renovar o morir) presente en los planes de estudio, en los proyectos de practicas, en los programas de innovación educativa, en los modelos didácticos, en la evaluación, en la formación continua y permanente, en el funcionamiento del Centro, en la creación de grupos de estudio, en la búsqueda de nuevas ofertas educativas, en la existencia de la revista Aula de Encuentro, en la investigación, etc. Junto a la importancia dada a la participación.

- Las dificultades económicas, financieras y laborales como condicionante, pero sin impedir-creemos- por el talante de profesores, alumnos y personal una existencia presidida por la idea fundacional, por el deseo de renovación y por la vocación de servicio a SAFA.

Del trabajo en todo esto hablan estos primeros setenta y cinco años.

Ya se han realizado un buen número de actos (Encuentro deportivo con la Universidad Loyola, Conferencias del Aula «Fe-Cultura» sobre la responsabilidad social de la Universidad y sobre cómo esa responsabilidad y la educación en la justicia se han trabajado a lo largo y ancho de 75 años, Campaña nueve meses nueve temas, Noche de oración de Magisterio, Realización de un mosaico con las fotografías de los alumnos actuales conformando el anagrama del 75 aniversario en el Patio de columnas, pero quedaría lo más importante por lo que pueda tener de permanente: Publicación de la 


\section{DE ENCUENTRO}

Almagro García, A. (2019). Setenta y cinco años del Centro Universitario. Aula de Encuentro, no 21, volumen 1, pp. 1-4.

DOI:

historia del Centro Universitario bajo el título Educar para educar en SAFA (1944-2019). Del seminario de Maestros al Centro Universitario; Exposición de paneles reflejando la aventura histórica del Centro Universitario, con vocación de que se convierta en permanente; Nombramiento (pretendido) por parte del Excmo. Ayuntamiento como Entidad Ejemplar de Úbeda, al entender que guardamos con la ciudad especiales lazos históricos, además de haber destacado por el compromiso con el desarrollo y bienestar de Úbeda y su comarca y con el fomento de los valores humanísticos que le son propios; y, evidentemente, la Celebración de un Acto Institucional, en el mes de noviembre próximo, en el que esperamos se aúnen el reconocimiento, el empeño de futuro y la presencia de todos los protagonista de esta larga historia.

Creemos firmemente que debemos sentirnos dichosos por esta importante efeméride, porque, de una u otra forma, hemos sido y somos protagonistas, constructores y beneficiarios de una realidad: la de nuestro Centro Universitario, una institución tan venerable por su historia y por sus fines como joven por sus ilusiones. 